\title{
Moving from Competing to Complementary: Understanding the Influence of Personal Narratives when Designing Leadership Studies Curriculum
}

\author{
Nyasha M. GuramatunhuCooper, Ph.D. \\ Assistant Professor of Leadership Studies \\ Kennesaw State University \\ Linda M. Lyons, Ed.D. \\ Director of Strategic Initiatives and \\ Assistant Professor of Education \\ Kennesaw State University
}

\begin{abstract}
Leadership Studies education is a highly personal endeavor shaped by the personal experiences and philosophies of leadership educators. However, when course design collaboration opportunities are presented, teaching approaches and curriculum prioritization may be at odds because of distinct personal narratives. This article frames disagreement over course design as an unexpected yet useful tool for facilitating individual and collective examination of leadership educators' narratives and how they inform teaching and curriculum priorities. Drawing from standpoint theory and positionality, this work emphasizes that questions about how and what to teach in a leadership course are influenced by life experiences of leadership educators.
\end{abstract}

\section{Introduction}

Our story begins from a place of disagreement. We are Leadership Studies educators at a large public university in the United States. As colleagues, we teach in an academic Leadership Studies program that offers a certificate program as well as elective courses. In 2014, we were assigned to teach separate sections of a course on leadership in a global society. In preparation, we met to discuss the course description, selection of a textbook, learning objectives, as well as the general themes to cover during the semester. Our initial meetings revealed that we had different ideas about how to teach the course. Holding strongly to our views, we each advocated for emphasizing certain content, leaving the following question unanswered: "What do students need to know about leadership in a global society?"

After several rounds of discussions, we realized that we had an opportunity for scholarly inquiry. Through reflection, we learned that our individual positions were heavily influenced by our life experiences. What seemed to be a disagreement was actually reflection and emergence of the personal experiences and areas of expertise we were bringing to the course. Embedded within knowledge about positionality and standpoint theory, and unearthed through agency and reflection, our work presents pivotal parts of our personal narratives as a way of mapping our 
worldviews and reflecting on how they influence our approach to teaching about leadership in a global society.

\section{Situating Our Disagreement}

The practice of teaching leadership is both private and public. It is private in that it is created out of one's experiences, values, and beliefs. It is public in that these same experiences, values, and beliefs are brought into institutionalized learning spaces that engender curiosity, vulnerability, interrogation and disruption of the status quo, new ways of learning, and sometimes allows for the critique of one's current frame of reference. Palmer (1998) refers to this duality as the inner and outer landscape of teaching. Rendon (2009) presents the inner landscape as a relation to self: ". . . who we are, what we hold most dear, and our sense of purpose and meaning." Necessarily complementary is the outer landscape, fed by the inner: "... what we do with our minds, and is usually associated with intellectualism, rationality, and objectivity" (p. 7).

Within the motions of physically entering into the learning space, we advance that Leadership Studies educators bring with them a teaching practice that exists in duality: birthed out of a postmodern amalgam of experiences with people, places, things, and events (the private). Recognizing this, each educator's teaching practice and philosophy is a vehicle for challenging pedagogy when it encounters another's uniquely formed and inspired teaching practice and philosophy (the public). When this occurs, an ideological chasm might present itself wherein the need to convey the right way to teach leadership takes primacy because at this point, the personal (inner landscape) comes at odds with another's presentation of the personal.

There is no malice in this chasm, for it is merely a representation, yet unrecognized, of the differences in experiences that Leadership Studies educators embody. Without this realization, there comes an insistence on how and what to teach, at times using institutional and programmatic outcomes to lay claim to a particular way of instruction or body of knowledge. In essence, this positions Leadership Studies education as a contested site wherein approaches, learning outcomes, and content can vary (and at times be at odds) between and amongst leadership educators.

When the private (inner landscape) collides with the public (outer landscape), disconnection between teaching approaches causes missed opportunities for innovation, mindful teaching, and epistemological diversity, which is the hallmark of a growing discipline that is influenced by historical, social, political, and cultural contexts. However, all is not lost. This collision, when reflected upon, presents an opportunity to create space for different ways of knowing and being that positively influence the ways in which leadership is conceptualized, taught, and practiced.

In this article, we examine how our lived experiences have shaped our pedagogical approaches to teaching leadership in a global society. Learning about these influences helped us to understand why we wanted to teach the course in different ways. As Rendon (2009) noted: "Sharing the stories of our humanity opens us to a deeper connection with others and ultimately to ourselves" (p. 51). This exhortation takes on urgency in our work as we are reminded of Ospina and Foldy's reference of the importance of demonstrating multiperspectivity and 
diversity in thoughts and experiences that are part of our discipline without "suppressing difference" (as cited in Crosby, 2011, p. 82).

\section{Conceptual Framework}

Day, Kingston, Stobard, and Simmons (2006) reaffirm Crosby (2011) by noting that there is an inextricable link between professional and personal identities. We understand this to mean that our life experiences, rooted in different parts of the world and at critical moments within our respective societies, influence the way we teach leadership in a global society. As such, we cannot divorce ourselves from our lived experiences when we teach Leadership Studies courses. We explore the emergence of our Leadership Studies educator identities and pedagogical approaches from two theoretical perspectives: positionality and standpoint theory. As two Leadership Studies educators, we bring a "situated sense of self that is shaped by our cultural experiences and social locations" (Sorrells, 2016, p. 12).

Positionality, at once simple and complex, is the idea that social location, along with perceptions and experiences of race, class, gender, sexual orientation, religion, nationality, and physical abilities, impact how one moves about in and understands the world (McLaren, 2003). For example, as Black women, we have different ethnic identities (African and African American), different educational backgrounds, distinctive career trajectories, diverse life experiences, and unique leadership teaching approaches. In its scope, positionality is relational. In this space, be it physical or ideological, we think about how we are situated in relation to others within the socially constructed categories of race, gender, class, sexuality, citizenship, ethnicity, nationality, religion, and ableness (2003). Closely connected to positionality is standpoint theory, which was first introduced by Patricia Hill Collins (1986): a preeminent feminist scholar. Collins defined standpoint as a place (physical, ideological, or a hybrid) from which one views and makes sense of the world. Standpoint is pervasive and necessary to acknowledge because it influences what we see and what we cannot, do not, or choose not to see (1986).

Using positionality and standpoint theory helped us to understand the validity of both of our perspectives. Positionality and standpoint theory freed us, as the subjects of this inquiry, from thinking that either of our perspectives were wrong. We were simply operating from the cultural and social contexts that shaped our lens. hooks (1994) names this as "multiple ways and multiple references" (p. 36). At this point, it is important to acknowledge that we are using an abridged version of standpoint theory and are removing it from its context of critical feminist theory, however, the transfer of knowledge helps us to understand the ways in which our individual narratives, leading to our approaches in this course, are constructed, reinforced, presented, and challenged.

\section{Unveiling}

Our unveiling follows two forms: we formally sat down and tried to understand each other, and we also take on agency by telling our stories in this piece. In formally sitting together (at a table in a conference room with a recorder) we stepped into the world of auto-ethnography. The theoretical framework of auto-ethnographic research: personal narratives of people, which are 
examined in a particular cultural context that speaks to one's own experiences and perspectives (Rashid, Caine, \& Goez, 2015; Poulus, 2013), was used in our inquiry. Hayano defines autoethnography as a focus on oneself as a member of a social group or culture, and hence a study of one's own group (as cited in Rashid et al., 2013), and the many relations that one has with personal, professional, organizational groups and other situations and contexts (Purdy, Loffredo, Halley, Holmes, \& Christy, 2016). Pavlenko (as cited in Mendez, 2013) postulates that autoethnography gives access into an individual's private world while providing rich data. In our case, "the researcher calls on his or her own experiences as the source from which to investigate a particular phenomenon" (Mendez, 2013, p. 282).

When approaching our course design and debating how to move forward with our process of developing leadership curriculum, we recognized that our individual positions were heavily influenced by our cultural backgrounds, specific training, and life experiences. To move beyond these differences, there was a need to build synergy by understanding each other's unique viewpoints in order to design the course. It became apparent that we would need to share our individual stories and "engage in the cultural analysis and interpretation" (Chang, 2008, p. 43 ) to understand their impact on our work as Leadership Studies educators. Through this twoway communication of sharing cultural background and critical incidents that have shaped the way we each teach, using auto-ethnography research was the appropriate choice in giving deeper insight and understanding of our individual lived experiences and pedagogical approaches.

The sections that follow present our narratives and their impact on our pedagogical approach to teaching leadership in a global society. However, before this undertaking, it is critical to exercise agency and introduce ourselves and our connection. The purpose of this exercise is to recognize and acknowledge the institutional context in which we as Leadership Studies educators exist and function. Our course, Leadership in a Global Society, is an upper division course in a certificate program within an academic unit at a large public institution in the Southern region of the United States. Students may take the course as an elective or as part of the certificate program. Our students come from various majors and career fields. The purpose of the program is to facilitate scholarly informed practice of leadership across disciplines and contexts. Within this space, our Leadership Studies faculty reflect the diversity of the students in the program through expertise, experience, citizenship, gender, and philosophies about Leadership Studies. We name this diversity because, as the theme of our work has thus shown, it influences how we teach leadership. In resolving our initial disagreement and reaching the state of complementary, we decided to forego creation of a standard curriculum format and to incorporate elements that highlight our specific areas of expertise and experiences. In the following section, we introduce ourselves and discuss the approach we each took in teaching this leadership course.

Nyasha. I, Nyasha GuramatunhuCooper, serve as a tenure-track faculty member in the department of Leadership and Integrative Studies at Kennesaw State University. I teach courses in Leadership Studies, emphasizing the theoretical frameworks of the discipline. My formal training in the discipline comes from a doctoral program in Leadership Studies. In crafting my teaching, research, and scholarship, I am drawn to conceptualization and practice of leadership in global contexts, specifically examining the social, cultural, and historical contexts of leadership. I am committed to invoking the value and strength of non-Western perspectives of leadership in 
a discipline that has a Western bias. In my work, I incorporate ways of knowing and being from the Global South because that is where I come from, that is what I know, and that is what I do not see represented in my discipline.

The ideas of scholars such as bell hooks, Juana Bordas, Jean Chin, Joseph Trimble, Paulo Freire, Edward Said, Homi Bhabha, and Molefi Asante have taught me that how and where one is positioned in the world matters (particularly from cultural and social contexts), and it necessarily and critically influences how one conceptualizes and practices leadership. In merging my research interests and course content, I emphasize the importance of understanding the cultural and social contexts in which leadership takes place. I am intentional and consistent about using materials that represent Non-Western and global contexts so that students can appreciate leadership as a concept and practice that means different things to different people at different times, and cultivate knowledge, skills, and awareness to understand that leadership is a culturally and socially mediated practice that responds to its environs.

Within the context of our work, I chose to teach my section through a critical analysis and understanding of culture and its impact on leadership. I wanted learners to understand how culture, in its pervasive nature, impacts conceptualizations and practice of leadership. My assumption was that learners, particularly given the interconnectedness afforded by rapid globalization, would no longer have the luxury to decide if they wanted to engage with different cultures. Rather, the reality of $21^{\text {st }}$ century personal and professional environs has made it such that interaction with people from other cultures is inevitable (Liu, Volcic, \& Gallois, 2015). An example I often give in class is that the American college campus is now home to students, staff, and faculty of different cultures. I will often ask, "How many have had a class with a professor who was born in another country? How many have had a neighbor, friend, coworker, roommate or classmate from another country? How many have lived, worked, or traveled in a different country?" Inevitably, all the hands in the classroom go up, including my own. From my perspective, critical cultural understanding, beyond a pedestrian chorus of "We should appreciate differences," was and is critical to leadership in a global society. I wanted students to understand how culture, in its visible and invisible forms, influences how one navigates the world, how one is included or excluded, and ultimately, how one conceptualizes and practices leadership within various contexts. In some ways, I was saying to my learners, "It is wonderful that you are interested in leadership, but you need to understand how the world works from a cultural and social perspective." I suppose this was a projection of my own identity and experiences as a bicultural and multilingual woman of color in the academy. I use the word projection in a positive way: to own that my experiences influence how and what I teach (White, Zion, \& Kozleski, 2005).

I was born and raised in Zimbabwe, a southern African country with a population of about 12 million. My cultural identity is steeped in rich traditions of the Shona people, from the Eastern Highlands of Zimbabwe and from neighboring Mozambique. Among the 15 British colonies in Africa, Zimbabwe was the last to gain independence (Blair, 2002). As with many African states, Zimbabwe's colonial history is long and complex (Sibanda, 2005). Cecil John Rhodes and a group of British settlers entered Zimbabwe in 1890 seeking to build a "British empire that would stretch from Cape to Cairo" (p. 19). Rumors of the availability of gold in abundance led Rhodes to claim the territories of Mashonaland and Matebeleland (Modern day 
Zimbabwe) as Rhodesia, a state bearing his name (2005). Rhode's entry into Zimbabwe marked the beginning of 90 years of colonial rule over the Shona and Ndebele people of Zimbabwe "with full blessings from the British crown" (p. 26). I bring this historical knowledge to bear because my cultural identity is influenced by colonial influences.

I have spent significant time away from Zimbabwe. I immigrated to the United States when I was 14 and moved to Pocatello, Idaho. Higher education took me to the states of Georgia and Washington, and my partner's career took me to Germany for three years. During this time away from Zimbabwe, I began to earnestly think about my cultural self as I navigated life in different geographical spaces and took note of my interactions with others. I took note of how I responded to others, how others responded to me, and how my space (country or state) influenced these interactions. Shankman, Allen, and Haber-Curran (2014) have detailed this pivoting as consciousness of self, other, and context.

While living in Zimbabwe, I admit that I did not actively think about my cultural identity because I was in a space where everyone else shared the same cultural identity. However, distinctions of family clan/totem, rural/ancestral home, language, and class made it so that there were elements of cultural familiarity rather than complete similarity. In Zimbabwe, my cultural identity was fixed and I adhered to the norms, customs, and expectations of a collectivist society where everyone had a role to play, power distance was high, the politics of patriarchy made a feminine-oriented society sometimes masculine, and a distinct preference for short term orientation in the forms of traditions, and great aversion to risk (Hofstede, 2011). Because of the element of high power distance, leadership was positional and grounded in age, station in life, and perceived or real authority.

When I moved to the United States, I moved to Pocatello, Idaho. This was a very big shift for me. Because I did not have the language to process the cultural shift that was taking place, I went through what I now recognize as assimilation. I stood out in every way imaginable: I had an accent, I was one of two Black children in the school, and I was the youngest in my grade level. I found that my peers, who were also trying to make sense of my existence in their space, struggled with lack of knowledge about Zimbabwe, about Africa, and about me. In an effort to fit in, I tried to understand what it meant to be American and what was expected for me. I practiced what I now understand to be assimilation (Waters \& Jimenez, 2015).

In my quest to become part of the in-group, I did not prioritize my cultural identity and I did not understand why this was necessary. This can be attributed to the fact that I was a teenager who did not have the language to parse and frame the significance of cultural and social nuance. I failed to understand that I was now required to shift my orientation in cultural dimensions (Hofstede, 2011). For example, I was now living a society that valued individualism and exceptionalism, and there was considerably low power distance. It was a foreign concept that I could directly address someone in a perceived position of authority, or even call them by their first name without some sort of consequence.

After living in the United States for a while, I began to embody what Bhabha (1994) calls the "third space." As my experiences increased in professional and personal spaces, I moved from assimilation to acculturation (Berry, 2005). I was still governed by my Zimbabwean 
cultural and social values because such is the nature of cultural influence: it cannot be easily shed or discarded. However, I could sense the development of my bicultural self as I pivoted between Zimbabwean and American cultural norms. As I write, I do not quite belong to both places but I have been able to create a hybrid cultural identity that allows me to adapt to my two cultural influences (2005).

I lived in Germany between 2011 and 2014. In this space, my cultural identity and social context once again shifted. I was both a Zimbabwean and an American living in a Germany. At any given time, and as different social interactions required, these three cultural influences were at play. Because I frequently traveled between these three places and other parts of the world, I was hyperaware of differences in culture and could point out how these differences impacted my interactions with others. For example, I was careful to mind social boundaries and kept our conversations to the business at hand when speaking to my German neighbors. I could be more informal and could share personal details at will in order to make connections when speaking to my American colleagues. Within my Zimbabwean interactions, I had to be aware of hierarchy and consider how my actions would impact others associated with me.

My experiences living in three different countries and cultures serve as a catalyst for my stance on the importance of facilitating leadership education that prizes critical understanding of cultural and social nuances. Reflecting on my cultural experiences has been an important resource for the way I approach teaching about leadership in a global society. Guided by my worldview, querying culture and its various elements is at the heart of examining the breadth and depth of leadership in a global society. Drawing from the emotionally intelligent leadership model (Shankman, Allen, \& Haber-Curran, 2014), this focus on culture is an impactful teaching vehicle in helping students understand their cultural selves, the ways in which they engage with other's cultural selves (positively or negatively), and how contexts (particularly when social nuances are considered) either interrogate or complement perceptions of leadership.

In helping students recognize their cultural selves, I employ tools such as the "Name Game." My own name, Nyasha (meaning Grace or Mercy), Guramatunhu (to travel across lands) tells the story of my cultural identity, and I bring that with me in my teaching. In telling the story of my name, it reveals my linguistic, cultural, and geographical affiliation. I ask students to share the story of their names and how that influences how they navigate the world, with emphasis on their cultural selves because these cultural identities are an integral part of leadership (Chin \& Trimble, 2015). Ultimately, I am asking students to think about how their culture influences how and what they think about leadership.

I also introduce students to different ways of knowing and being. For example, I use the concept of Afrocentrism as a means to explore how different worldviews can impact who is considered a leader and what is considered leadership. Using concepts such as Afrocentrism and cultural imperialism within a Leadership Studies classroom functions as a way to create connections across disciplines, but it also facilitates understanding that historical and seemingly removed concepts can have contemporary applications and manifestations within leadership.

Films that have a cultural and social component embedded within non-Western milieus (as with my own upbringing) feature in my instruction of leadership in a global society. I have 
used the film Invictus (2009), loosely presenting facets of Nelson Mandela's presidency, as a way to guide students to think about the connection between leadership and culture, and the various ways of leading that are present within a global society. Invictus, though in a very limited way, guides students into seeing leadership within a different social and cultural context. I am careful to frame this opportunity as a chance to think about how our different parts of the world require different kinds of leadership, particularly when we consider how political and historical elements can shape and shift culturally influenced leadership.

My students have noted my focus on culture when teaching about leadership. Course evaluations show an appreciation for the different perspective that I bring to the learning community. Students have also noted that critically thinking about culture has helped them to self-evaluate their path to intercultural competency, with many noting how they overestimated their intercultural competence. Others have noted a desire to learn more about the impact of culture in their personal and professional interactions. This feedback is not an endorsement of my methods, and it does not assign a value to what I do. Rather, it is a manifestation of how my lived experiences have fed my teaching practice, and the ways in which my students have responded to my identity and my teaching.

Linda. I, Linda M. Lyons, also serve as a tenure-track faculty member at the institution. My home department is First-Year and Transition Studies with a joint appointment in Leadership and Integrative Studies. In addition to my teaching responsibilities, I hold administrative roles in my college as the Director of Strategic Initiatives and manage a five-week education abroad program to Montepulciano, Italy. I have built an academic trajectory focused on the scholarship of teaching and learning related to multicultural education. The courses I teach emphasize theoretical frameworks that focus on the development of leadership skills as well as intercultural competence to and with incoming students as well as upper classmen. I use frameworks such as Deardorff's (2011) multicultural competence and intercultural maturity theory, Bennett's (1986) Developmental Model of Intercultural Sensitivity (DMIS), and Banks' (1993) five dimensions of achieving cultural awareness to facilitate global learning. My research agenda involves three interconnected threads: (1) leadership and group development; (2) promotion of cross-cultural awareness through education and experiential learning; and (3) the use of collaboration and appreciative inquiry best practices in work group settings. My formal training comes from a doctorate in Adult Education with an emphasis in leadership and organization development. I have held administrative responsibilities that include Director of Training and Professional Development, Interim Chief Diversity Officer, and leading teams to address specific organizational performance issues, both on my college campus and at the Board of Regent's state-level.

It was in my role as Interim Chief Diversity Officer that I was fully exposed to and mindful of other aspects of diversity beyond racial issues. Langer and Moldoveanu (2000) indicate that the state of being mindful occurs when one actively processes information, is open to new ideas and insights, and sensitive to context. The experience expanded my thinking of how diversity is much broader than race, but also includes, abilities, sexual orientation, gender issues, and social/economic differences. This role also inspired me to pursue deeper knowledge in multiculturalism as well as build my own intercultural competence. To further gain these skills, I participated in several study-abroad experiences, both with students and faculty 
programs. The first time I went abroad was to the Republic of Ghana in 2007 during the $50^{\text {th }}$ anniversary of independence from Britain. I was exposed to the rich Ghanaian culture and the experience made me feel honored to be part of such a historical occasion. During the course of the trip, we visited with students from the University of Cape Coast and toured Elmina Castleone of the ports for the Atlantic slave trade during the $15^{\text {th }}$ through the $19^{\text {th }}$ centuries (Osei-Tutu, 2006). It was at this point where I realized that my perspective around the history of slavery, as an African American, was very one-sided and that I knew very little of other cultures, let alone how that influences and compares to my own culture. I experienced culture shock that forced me to acknowledge my personal biases and reflect deeper on cultural differences. By recognizing culture shock, as a defensive response to the dissonance that occurs when one's world view is challenged, it is possible to learn to develop methods of channeling shock into personal growth (Bennett, 1977). After my visit to Ghana, I was inspired to experience cultural differences through study abroad experiences. I have also traveled to Brazil and Nigeria and have bridged my international travel experiences into my global leadership curriculum.

There are several key life experiences and critical incidents that formulate my personal narrative and greatly influence my teaching within the Leadership Studies curriculum. I was born and raised in a middle-class family in Washington D.C. As a Washingtonian, I was exposed to all the cultural and political facets that D.C. has to offer. During the late 60s and early 70s, childhood experiences created critical incidents that laid the foundation for how I perceive race relations, openness to diverse worldviews, and how I approach teaching multicultural education. Both of my parents worked in the federal government system. My father was an artist for the Department of Oceanography at the Navy Yard, and my mother worked as an administrative assistant with the Department of Defense at the Pentagon for 33 years. My older brother and I often heard conversations at the dinner table about politics, social justice, work ethic, and the importance of education. My grandparents were proud parishioners of the Mennonite church, and my grandfather made history as the denomination's first AfricanAmerican ordained bishop. One of my aunts was the first African-American to graduate from Goshen College (a predominately white campus in rural Indiana) in 1943 during a time when racial segregation was prevalent in many parts of the United States. I heard and listened to many stories about my family and their courage to achieve so much during a time when opportunities were not readily available to African Americans. My family's foundation, built upon spirituality, determination, endurance, discipline and perseverance, instilled in me the importance of education, excellence, and the use of critical thinking skills when deciphering information. Most importantly, I was taught to never be afraid of voicing my thoughts.

I was introduced to racism at a very early age. I witnessed Dr. King's 1963 "I Have a Dream" speech, and five years later, observed the D.C. race riots as a result of his assassination. I was called a nigger at the age of thirteen during a youth ministry trip to Buffalo, New York. I did not fully understand the dynamics of this racial slur at the time, but felt the anger and threats around how the word was conveyed to me. Because of these childhood memories, diversity and inclusion are pivotal frameworks in my global leadership teaching philosophy, and ultimately, how I chose to teach the Leadership in a Global Society course.

During the late 1970s, colleges and universities throughout the country were providing financial scholarships to minorities to change the demographics of their enrollment. I was 
recruited by and got accepted to the University Oklahoma (OU) as an undergraduate student. At that time, my purpose for attending OU was a desire to chase tornados and obtain a degree in environmental studies, which both the state and school provided. I also have family in Oklahoma, so I felt comfortable with my transition to this region and thought it would not be too difficult adjusting to my new environment. I connected with family and others within my own race while attending OU. Most notably, I built relationships with Native Americans living in the region. This afforded me a chance to learn about their culture and heritage, something that I do not think would have occurred if I had remained in the Washington D.C. area. It was during these interactions that I realized that my perceptions about Native Americans were based on what I saw on T.V. and were wrong and very limited. Allen (2011) frames this incomplete knowledge in this way: "we usually don't realize we've assumed anything until something contradicts that assumption" (p. 1). I also felt like an outsider in Oklahoma. In this part of the country, my East Coast accent was often viewed as something strange and unique. I was teased about how I pronounced specific words and constantly told that my style of dress was an anomaly. These critical incidents gave me new insights around differences and how my perception about diversity being strictly based on race was one-sided.

I moved to Atlanta, Georgia in my mid-twenties. At that time, I lived outside of the Atlanta city limits. During my first week, I encountered the Klu Klux Klan distributing brochures on a street corner, about two miles away from my apartment. As time went on, I also experienced personal bias and racial profiling. When working as an executive assistant for a Vice President at a nonprofit organization, I was appointed as a board member of a professional organization that specialized in supporting executive assistants. I was the only woman of color on the Board. Our meetings were often held at popular and exclusive restaurants and country clubs throughout the city. At one specific board meeting, I entered the building of an upscale establishment and was told to wait for authorization to enter, while White club members and colleagues in my professional organization were allowed entry. If it were not for the president of my Board asking the security guard why I was not allowed to come in and verifying my association with the group, I am sure that I would have either been further detained or denied entrance. This and other direct incidents of racism that I encountered in my earlier days of living in Georgia, along with the social dynamics occurring in the metropolitan area at the time, made me revert back to my frame of reference around diversity being strictly a race issue. I was compelled to take a more active role in my community by participating in protest marches addressing racism and inequality, as well as volunteering with organizations that promoted inclusiveness.

These incidents, as well as my travels abroad, inform my teaching philosophy. As an educator, I have become aware of the changing demographics of students in higher education, thus broadening my understanding of diversity. In teaching Leadership in a Global Society, I chose to highlight the layers of diversity and their impact on leadership. In response to my students and my own learning about the nuances of diversity, my goal is to provide a learning environment that will cultivate new knowledge and provide a foundation for lifelong learning skills. To accomplish this, I apply a wide variety of learning strategies and theories that take into account a student's level of learning and previous experiences that may be influenced by their race, ethnicity, gender, as well as their understanding of cultural awareness. In noting the changing demographics of students, it is also important to pay attention to issues of ageism when 
teaching both traditional and non-traditional student populations, as well as addressing the learning needs of first generation students (Ishitani, 2003). Drawing from my research interest, building intercultural competence in higher education has allowed me to use theory, best practices, and experiential learning into my course design. For example, I incorporate TingToomey's (1999) Iceberg Model as a reflective exercise in the Leadership in a Global Society course for students to think deeper about cultural differences. This model uses the analogy of viewing the top of an iceberg as only visually interpreting what is seen about individuals or various cultures on the surface. In continuing with the metaphor, I facilitate discussions about the model's emphasis on looking below the surface of the waters around an iceberg in order to see and have a deeper understanding of culture differences beyond what is viewed on the surface (1999). I often refer to Bostrom and Clawson's (n.d.) idea that effective leaders have the ability to look at worldviews from a number of different perspectives - self (the view from one's own perspective), other (the view from the other's perspective), and observer (the view from an outsider's perspective or neutral position).

In my Leadership for a Global Society course, learning outcomes state: (1) exploring how diversity and cultural context affect leadership style, skills, knowledge, and practice; (2) examining their own attitudes and biases to discover their multicultural awareness; (3) recognizing the importance of the variety of leadership styles in a growing global society and; (4) increasing their awareness of leadership attributes surrounding domestic and global issues. I also share personal experiences with students to emphasize the learning objectives. One example of achieving this was stated by a student in a course evaluation: "Dr. Lyons is helpful and good at making class interesting and interactive. She connects some of the topics to experiences in her own life which makes it easy to relate to her." By sharing my life experiences related to diversity and inclusion, this gives students an avenue to freely express their narratives and critical incidents as they relate to the class.

\section{Reflecting to Understand}

After presenting our narratives to each other, we both took time to reflect on what we learned about each other. In learning about the other, the differences we had in approaches to teaching the course took on a new form. They were necessary differences that highlighted our individual selves. The gift of our stories to each other symbolizes a meeting place. This meeting place is where we heard each other's narratives and essentially met the identities that we bring to our leadership educator roles. When two ethnically diverse individuals come into contact in the workplace there can be a new appreciation and understanding of the other perspective, which can lead to mutual acquaintance and acceptance (Vassou, Zopiatis, \& Theocharous, 2017). What follows are our reflections to each other's stories.

Linda. When I met Nyasha, my first impression of her was that she was a strong willed, confident, and highly intelligent Black woman. These are traits that I continue to admire about her and other professional Black women. At the onset of our work, I wanted to build upon common experiences as Black women in the academy, particularly in our quest to design and deliver Leadership Studies curriculum. However, I failed to recognize that her story was unknown to me and to the other Black women I associate and have worked with in higher education. In emphasizing the common experiences, the result was a minimization of our 
differences, which impacted true understanding of cultural differences (Hammer, Bennett, \& Wiseman, 2003). Rock, Grant, and Grey (2016) emphasize this point: "When people with different perspectives are brought together, people may seek to gloss over those differences in the interest of group harmony, when in fact, differences should actually be taken seriously and highlighted" (p. 4). It was not until we were at a crossroads in our approach to developing the Leadership in a Global Society course that I realized our differences were a significant part of our interactions with each other and that these unique distinctions would have to be recognized and some form of mutual understanding needed to take place to meet our charge successfully.

Understanding Nyasha's personal narrative helped me gain clarity and a deeper respect for the perspectives that she brought to our collective work. Learning more about Nyasha's life in Zimbabwe and the dissonance she experienced when coming to the United States at an early age gave me better insight into why she demonstrates continuous pride for her country as well as educating others about its rich history. It is hard for me to place myself in that position because my pride for my country continues to be altered and influenced by the ongoing occurrences of injustice and inequality around race, ethnicity, age, disabilities, and gender. I recognize and appreciate the strength and courage it takes to make such a transition into a different social and cultural environment while still maintaining the space for one's own cultural identity. Her travels across the globe and her emergence into various cultural settings also highlights her ability to bring additional multicultural perspectives into the classroom. Learning more about Nyasha's background and personal experiences through her non-Western lens has allowed me to pause and reflect on my own cultural experiences, personal biases, as well as global mindfulness.

Nyasha. In listening to and reflecting on Linda's story, I noted an internal reaction that stayed with me. I name this internal reaction as a sense of awe as I realized that my colleague's narrative was rooted in some of America's most pivotal moments. I recall hearing Linda's recollection of living in Washington D.C. and going to the National Mall to hear Dr. Martin Luther King Junior speak, and witnessing the riots that followed after his death. I cannot imagine the intensity and sacredness of those moments and the impact they leave on one's life. Linda's emphasis on teaching to diversity and the changing demographics of the student population made me think of the changes that she had seen in this country, things that I am now only coming to fully appreciate because of my immigrant background.

When Linda proposed a focus on diversity, I failed to recognize the particular context in which she had been brought up, as well as her experiences as a woman of color both in the academy and industry. She noted an earlier understanding of diversity through a racial lens, and I now understand why. There is no way to minimize the impact of growing up as a Black child in Washington D.C. at a crucial time in the United States' engagement with racial injustice and inequality. Within this particular context, diversity through a racial lens is important. Though we share the same racial identification, the fact that I grew up in Zimbabwe, a predominantly Black society (albeit its colonial history) meant that (and in some cases still means) that I have a developing sense of understanding the racial aspect of diversity in the United States.

Linda noted that she shares some of these experiences with her students. I believe that this is a powerful tool that brings diversity concepts to life. There is a richness that comes from personal stories that cannot be duplicated in a textbook. As I reflect, I realize the value in 
emphasizing diversity through Linda's experiences. Her experiences bring the notion of a global society closer to our students in that most of our students are citizens of the United States (born and raised), so her experiences growing up in this country (and because they are embedded within a historical and social context our students can readily access) create a bridge for students to understand the complexity of diversity. In noting the changing demographics of students, I see Linda as yet again situated in the pivotal shifts within the United States. Addressing the global learning needs of first generation students and adult learners is a diversity issue, and I appreciate Linda's commitment in pushing against limited notions of diversity. This has helped me to think of diversity as layered, rather than binary.

\section{Conclusion}

Our work can be useful in two ways: at a disciplinary and individual educator level. The idea of studying the identities of Leadership Studies educators is relatively new, with preliminary work by Chin and Trimble (2015), Seemiller and Priest (2015; 2017), and Jenkins and Owen (2016). It is important to continue this work because Leadership Studies education is not just about teaching concepts and theories, but also includes the individuals who teach and how their personal narratives greatly influence concepts and theories being taught. As the discipline grows, inquiry into the identities of leadership educators opens avenues to explore the different ways in which leadership is understood.

Just as students make their own meaning of the theories and concepts, Leadership Studies should also prize the personal experiences that leadership educators bring into the learning environment. An immediate way to do this would be to encourage reflective scholarship that invites educators to think about their own personal and professional experiences and how they impact their approach to teaching leadership. Professional conferences within Leadership Studies can make space for discussing educator identities as a way to acknowledge that leadership educators are a part of a socially constructed world and cannot maintain a neutral position in teaching. As Crosby (2001) noted: the personal and social identities "are never addons as we engage in leadership and followership" (p. 81). These same identities must be leveraged and encouraged because they expose students to different leadership perspectives and experiences beyond textbook material.

At the individual level, we encourage our colleagues to take time to reflect on the ways in which their personal narratives affect how they teach. Teaching in Leadership Studies is a relational act that requires all participants (educators and students) to acknowledge the presence of multiple perspectives and the subtle and overt ways they might impact how theories and concepts are supported, challenged, deconstructed, and reconstructed when faced with cultural traditions, interests, values, and pre-formed understandings (Alvesson, 1996).

Through a disagreement on how to approach the design and delivery of a course on leadership in global society, the dissonance provided an opportunity for us to examine how an instructor's (our) lived experiences (including academic, social, and cultural background) influence pedagogy, thematic focus, and assessments. These lived experiences illustrate the theories of positionality and standpoint, which prize how people, places, things, and events have a significant impact on how one views the world, and consequently, one how teaches leadership 
within the context of our work. Without understanding this framing, we could have missed an important opportunity to learn from each other as leadership educators.

\section{References}

Allen, B. J. (2011). Difference matters: Communicating social identity. Long Grove, IL: Waveland Press, Inc.

Alvesson, M. (1996). Leadership studies: From procedure and abstraction to reflexivity and situation. Leadership Quarterly, 7(4), 455-485.

Banks, J. A. (1993). Multicultural education: Historical development, dimensions, and practice. Review of Research in Education, 19, 3-49.

Bennett, J. M. (1977). Transition shock: Putting culture shock in perspective. In M. J. Bennett (Ed.), Basic concepts of intercultural communication, (pp. 215-223) Boston, MA: Nicholas Brealey Publishing.

Bennett, M. J. (1986). A developmental approach to training for intercultural sensitivity. International Journal of Intercultural Relations, 10(2), 179-195.

Berry, J. (2005). Acculturation: Living successfully in two cultures. International Journal of Intercultural Relations, 29, 697-712.

Bhabha, H. (1994). The location of culture. London, United Kingdom: Routledge.

Blair, D. (2002). Degrees in violence: Robert Mugabe and the struggle for power in Zimbabwe. New York, NY: Continuum.

Bostrom, B., \& Clawson, V. (n.d.). Power of leadership perspectives. Retrieved from: http://people.terry.uga.edu/bostrom/Leadership_Articles/Guiding\%20Beliefs\%20Paper.pdf

Chang, H. (2008). Autoethnography as a method. Walnut Creek, CA: Left Coast Press.

Chin, J., \& Trimble, J. (2015). Diversity and leadership. Thousand Oaks, CA: Sage Publications, Inc.

Collins, P. (1986). Learning from the outsider within: The sociological significance of black feminist thought. Social Problems, 33(6), 14-32.

Crosby, B. (2011). Teaching leadership: An integrative approach. New York, NY: Routledge.

Day, C., Kingston, A., Stobart, G., \& Sammons, P. (2006). The personal and professional selves of teachers: stable and unstable identities. British Educational Research Journal, 32 (4) 601-616. 
Deardoff, D. (2011). Assessing intercultural competence. New Directions for Institutional Research, 149, 65-79.

Eastwood, C. (Director). (2009). Invictus [Motion Picture]. United States: Paramount Pictures.

Hammer, M. R., Bennett, M. J., \& Wiseman, R. (2003). Measuring intercultural sensitivity: The intercultural development inventory. International Journal of Intercultural Relations, 27(4), 421-443.

Hofstede, G. (2011). Dimensionalizing cultures: Hofstede model in context. Online Readings in Psychology and Culture, 2(1). doi:10.9707/2307-0919.1014

hooks, b. (1994). Teaching to transgress: Education as the practice of freedom. New York, NY: Routledge.

Hughes, H. (2012) An expanded critical incident approach for exploring information use and learning. Library and Information Research, 36 (112), 72-95.

Ishitani, T. (2003). A longitudinal approach to assessing attrition behavior among firstgeneration students: Time-varying effects of pre-college characteristics. Research in Higher Education, 44(4), 433-449.

Jenkins, D. M., \& Owen, J. E. (2016). Who teaches leadership? A comparative analysis of faculty and student affairs leadership educators and implications for leadership learning. Journal of Leadership Education, 15(2), 99-113. doi: 1012806/V15/I2/R1

Langer, E., \& Moldoveanu, M. (2000). The construct of mindfulness. Journal of Social Issues, 56(1), 1-9.

Liu, S., Volcic, Z., \& Gallois, C. (2015). Challenges of living in a global society. In Kennesaw State University, Leadership in a global society (pp. 3-22). Thousand Oaks, CA: Sage.

McLaren, P. (2003). Life in schools: An introduction to critical pedagogy in the foundation of education. Boston, MA: Allyn \& Bacon.

Méndez, M. (2013). Autoethnography as a research method: Advantages, limitations and criticisms. Colombian Applied Linguistic Journal, 15(2), 279-287.

Olson, M. (2015). An auto-ethnographic study of "Open dialogue:" The illumination of snow. Family Process, 54, 716-729.

Osei-Tutu, B. (2006). Contested monuments: African-Americans and the commoditization of Ghana's slave castles. In J. Haviser and K. MacDonald (Eds.), African re-eenesis: Confronting social issues in the diaspora (pp. 9-19). London, United Kingdom: UCL Press. 
Palmer, P. (1998). The courage to teach: Exploring the inner landscape of a teacher's life. San Francisco, CA: Jossey-Bass.

Purdy, M., Roca M., Halley, R., Holmes, B., \& Christy, C. (2016). Listening is... five personal worlds of listening: An auto-ethnographic approach. International Journal of Listening 31(1), 1-18.

Rashid, M., Caine, V., \& Goez, H. (2015). The encounters and challenges of ethnography as a methodology in health research. International Journal of Qualitative Methods, 14(5), 116. doi: $10.1177 / 1609406915621421$

Rendó n, L. (2009). Sentipensante (sensing/thinking) pedagogy: Educating for wholeness, social justice and liberation. Sterling, VA: Stylus Pub.

Rock, D., Grant, H., \& Grey, J. (2016). Diverse teams feel less comfortable. Retrieved from: https://hbr.org/2016/09/diverse-teams-feel-less-comfortable-and-thatswhy-they-perform-better

Seemiller, C. \& Priest, K. P. (2015). The hidden "who" in leadership education: Conceptualizing leader educator professional identity development. Journal of Leadership Education, 14(3), 132-151. doi: 1012806/V14/I3/T2

Shankman, M., Allen, S., \& Haber-Curran, P. (2014). Emotionally intelligent leadership: A guide for students. San Francisco, CA: Jossey-Bass.

Sorrells, K. (2016). Intercultural communication: Globalization and social justice. Thousand Oaks, CA: Sage.

Sibanda, E. (2005). The Zimbabwe African people's union, 1961-87: A political history of insurgency in Southern Rhodesia. Asmara, Eritrea: Africa World Press.

Ting-Toomey, S. (1999). Communicating across cultures. New York: Guilford Press.

Vassou, C., Zopiatis, A., and Theocharous, A. I. (2017). Intercultural workplace relationships in the hospitality industry: Beyond the tip of the iceberg. International Journal of Hospitality Management. 61(2017), 14-25.

Waters, M., \& Jimenez, T. (2005). Assessing immigrant assimilation: New empirical and theoretical challenges. Annual Review of Sociology 31,105-125.

White, K. K., Zion, S., \& Kozleski, E. (2005). Cultural identity and teaching. Tempe, AZ Arizona State University: National Institute for Urban School Improvement. 


\section{Author Biographies}

Dr. Nyasha M. GuramatunhuCooper is a Leadership Studies scholar and educator. Her research and teaching explore connections between leadership and cultural contexts. In advancing the field of Leadership Studies, her work advocates for the addition of non-Western contexts of leadership by exploring the leadership narratives, experiences, and voices in Africa.

Dr. Linda M. Lyons manages the strategic planning process for her college and teaches leadership development courses that are germane to diversity and inclusion as well as multicultural education. Her research focus is exploring how learners build intercultural competence through their participation of global learning curricular and education abroad experiences. 